Research Article

\title{
Buckling and Vibration Performance of a Composite Laminated Plate with Elastic Boundaries Subjected to Local Thermal Loading
}

\author{
Yonggan Sun \\ School of Shipping and Naval Architecture, Chongqing Jiaotong University, Chongqing 400074, China \\ Correspondence should be addressed to Yonggan Sun; sunygqj@163.com
}

Received 19 February 2021; Revised 16 July 2021; Accepted 25 October 2021; Published 18 November 2021

Academic Editor: Traian Mazilu

Copyright (c) 2021 Yonggan Sun. This is an open access article distributed under the Creative Commons Attribution License, which permits unrestricted use, distribution, and reproduction in any medium, provided the original work is properly cited.

In this paper, a model is established for the calculation of the vibrations of a composite laminated plate with elastic boundary conditions subjected to local thermal loading. The model is based on first-order shear deformation theory using the finite element method. The influence of boundary conditions, heating area, and heating location on buckling and vibrations of a composite laminated plate was investigated, and there were two stages in which the critical temperature increased sharply during the transition from free boundary to simply supported and rigid fixed boundaries. The thermal buckling of locally heated laminated plates is generally not checked in practical applications unless the heated area exceeds approximately $10 \%$ of the total area of the plates. The stronger the boundary constraint is, the greater the influence of the heated area is on the vibrational frequencies of the composite laminated plate.

\section{Introduction}

Because of their excellent strength, stiffness, light weight, and malleability, plates made of composite materials have received increasing consideration for structural applications in aerospace, shipbuilding, and other areas of industrial engineering. However, composite material plates are often compromised by exposure to thermal loads. For example, temperature changes cause stresses on ship structures that cannot be ignored when at sea. There can be very large temperature changes in the work environment, and temperature stresses can be particularly large on main engines, auxiliary engine compartments, pipelines, LNG facilities, and so on [1].

Many paper results have been published about vibration, buckling, and static performance analyses of composite structures. Vangipuram and Ganesan [2] studied the buckling and vibration of a rectangular composite viscoelastic sandwich plate with different boundary conditions subjected to thermal loading. Jeyaraj et al. [3] investigated the vibration and acoustic radiation properties of composite laminated plates with different combinations of boundary conditions subjected to various thermal loads based on the finite-boundary element method. Shiau et al. [4] applied the finite element method to study the thermal buckling behaviour of composite laminated plates with different boundary condition combinations of simply supported and clamped edges, and the results indicated that the thermal buckling mode is mainly dependent on the E1/E2 ratio, fibre orientation, and aspect ratio of the plate. Biswal et al. [5] performed numerical and experimental investigations on the free vibration behaviour of woven fibreglass/epoxy laminated composite shells for C-C-C-C and S-S-S-S boundary conditions subjected to hygrothermal environments. The results showed that there was a reduction in the natural frequency of laminated composite shells with increasing temperature and moisture concentrations. Zhao et al. [6] utilised the first-order shear deformation theory to study the effects of temperature and humidity on vibration performance of orthogonal anisotropic laminated plates with four simply supported edges, and the influence of temperature on the vibration frequencies of single-layer plates was more obvious than that of humidity.

According to a review of the literature, most previous studies on composite laminated plates are confined to classical boundary conditions, such as free, simply 
supported, clamped, and their combinations. However, a variety of possible boundary supports encountered in practical engineering applications may not always be classical in nature, and they will always be elastic along the supports. Unfortunately, studies of the effects of elastic boundaries have mostly focused on the dynamic performance of structures, and to the best of the author's knowledge, to date, no paper has dealt with the buckling performance of structures with elastic boundaries. Moreover, the temperature distribution on the composite laminated plate is usually uneven. For example, as a hypersonic structure accelerates in the atmosphere, the plate boundary acts as a radiator when connected to the cooler substructure, resulting in the generation of aerodynamic heat on its surface [7]. Few studies have dealt with how local heating affects the vibration properties of composite structures. Over the last several years, rapid growth in the design of structures and industrial processes has required development of computational models that reflect practical engineering problems; therefore, it has great significance to study the buckling and vibration performance of composite laminated plates with arbitrary elastic edge supports subjected to local thermal loads. The motivation of this study is to solve these two problems.

It is commonly believed that the finite element method (FEM) is a powerful tool for solving complex problems because of its strong adaptability. Recently, Alimirzaei et al. [8] considered the nonlinear static, buckling, and vibration of viscoelastic microcomposite beams reinforced by various distributions of boron nitride nanotubes (BNNTs) with initial geometrical imperfection by modified strain gradient theory using FEM. Hirane et al. [9] employed a novel higherorder layer-wise finite element model for static and free vibration analyses of functionally graded material (FGM) sandwich plates. In this paper, the buckling and vibration behaviour of a composite laminated plate subjected to elastic boundaries was studied by the finite element method. The paper is arranged in four sections. Following this introduction, Section 2 provides the theoretical background of the composite laminated plate and elastic boundary, and the corresponding matrix representation is given. In Section 3, the effects of boundary conditions, heating position, and heated area on the buckling and vibration performance of composite laminated plates subjected to local thermal loading are discussed. The final section summarizes the main results of the paper.

\section{Theory}

2.1. Governing Equations. As shown in Figure 1, based on first-order shear deformation theory, the deformation field of the composite laminated plate can be expressed as follows [6]:

$$
\begin{aligned}
u(x, y, z) & =u_{0}(x, y)+z \phi_{x}(x, y), \\
v(x, y, z) & =v_{0}(x, y)+z \phi_{y}(x, y), \\
w(x, y, z) & =w_{0}(x, y)
\end{aligned}
$$

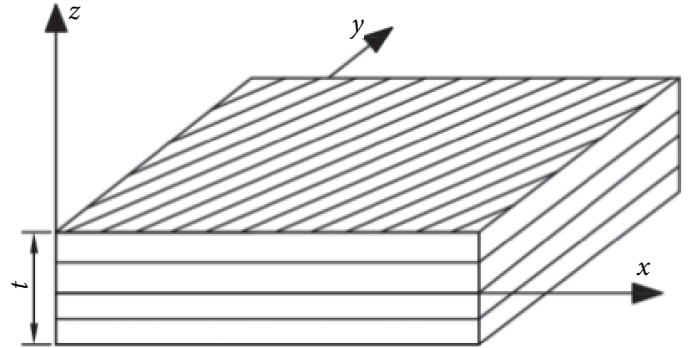

FIgURE 1: Schematic diagram of a composite laminated plate.

where $u_{0}, v_{0}$, and $w_{0}$ are the displacements of a generic point at the middle surface in the $x, y$, and $z$ directions, respectively. The bending rotations of a vector normal to the midsurface are denoted by $\phi_{x}$ and $\phi_{y}$ when measured in the $x-z$ and $y-z$ planes, respectively. Consequently, the strain-displacement equations can be expressed as follows [10]:

$$
\begin{aligned}
\varepsilon_{x} & =\frac{\partial u_{0}}{\partial x}+z \frac{\partial \phi_{x}}{\partial x}, \\
\varepsilon_{y} & =\frac{\partial v_{0}}{\partial y}+z \frac{\partial \phi_{y}}{\partial y}, \\
\gamma_{x y} & =\frac{\partial u_{0}}{\partial y}+\frac{\partial v_{0}}{\partial x}+z\left(\frac{\partial \phi_{x}}{\partial y}+\frac{\partial \phi_{y}}{\partial x}\right), \\
\gamma_{y z} & =\phi_{y}+\frac{\partial w_{0}}{\partial y}, \\
\gamma_{x z} & =\phi_{x}+\frac{\partial w_{0}}{\partial x},
\end{aligned}
$$

where $\varepsilon_{x}$ and $\varepsilon_{y}$ represent bending strains and $\gamma_{x y}, \gamma_{y z}$, and $\gamma_{x z}$ represent transverse shear strains.

The composite laminated plate is designed to be composed of $N$ layers. The thickness of each layer is $t_{k}$ so that $t=\sum_{k=1}^{N} t_{k}$ is the total thickness of the composite laminated plate. When the laminated plate is subjected to a constant temperature, the stress-strain relations of the $k$ th layer are of the form as follows [11]:

$$
\begin{aligned}
\left\{\begin{array}{c}
\sigma_{x} \\
\sigma_{y} \\
\tau_{x y}
\end{array}\right\}_{k} & =\left[\begin{array}{lll}
\bar{Q}_{11} & \bar{Q}_{12} & \bar{Q}_{16} \\
\bar{Q}_{12} & \bar{Q}_{22} & \bar{Q}_{26} \\
\bar{Q}_{16} & \bar{Q}_{26} & \bar{Q}_{66}
\end{array}\right]_{k}\left\{\begin{array}{c}
\varepsilon_{x}-\alpha_{x} \Delta T \\
\varepsilon_{y}-\alpha_{y} \Delta T \\
\varepsilon_{z}-\alpha_{x y} \Delta T
\end{array}\right\}_{k}\left\{\begin{array}{c}
\tau_{y z} \\
\tau_{x z}
\end{array}\right\}_{k} \\
& =\left[\begin{array}{ll}
\bar{Q}_{44} & \bar{Q}_{45} \\
\bar{Q}_{45} & \bar{Q}_{55}
\end{array}\right]\left\{\begin{array}{l}
\gamma_{y z} \\
\gamma_{x z}
\end{array}\right\},
\end{aligned}
$$

where $\sigma_{x}$ and $\sigma_{y}$ and $\tau_{x y}, \tau_{y z}$, and $\tau_{x z}$ represent the stress components and $\bar{Q}_{i j}$ are transformed reduced stiffnesses, which can be expressed in terms of the orientation angle and engineering constant of the material. For an in-depth discussion of the meaning of the laminate, see reference [12]. $\Delta T$ is the thermal load. $\alpha_{x}$ and $\alpha_{y}$ are coefficients of thermal 
expansion along the $x$ and $y$ axes, respectively, and $\alpha_{x y}$ is the apparent coefficient of thermal shear.

The stress resultants are as follows [11]:

$$
\begin{aligned}
& \left\{\begin{array}{c}
N_{x} \\
N_{y} \\
N_{x y}
\end{array}\right\}=\int_{-(t / 2)}^{-(t / 2)}\left\{\begin{array}{c}
\sigma_{x} \\
\sigma_{y} \\
\tau_{x y}
\end{array}\right\} \mathrm{d} z, \\
& \left\{\begin{array}{c}
Q_{x} \\
Q_{y}
\end{array}\right\}=\int_{-(t / 2)}^{-(t / 2)}\left\{\begin{array}{c}
\tau_{x z} \\
\tau_{y z}
\end{array}\right\} \mathrm{d} z,
\end{aligned}
$$

and the moment resultants are as follows:

$$
\left\{\begin{array}{c}
M_{x} \\
M_{y} \\
M_{x y}
\end{array}\right\}=\int_{-(t / 2)}^{-(t / 2)}\left\{\begin{array}{c}
\sigma_{x} \\
\sigma_{y} \\
\tau_{x y}
\end{array}\right\} z \mathrm{~d} z,
$$

where $t$ is the thickness of the composite laminated plate.

The total potential energy is the sum of the bending strain energy of the laminated plate and the potential energy of the laminated plate under the action of in-plane forces due to the thermal load, which can be expressed as follows [13]:

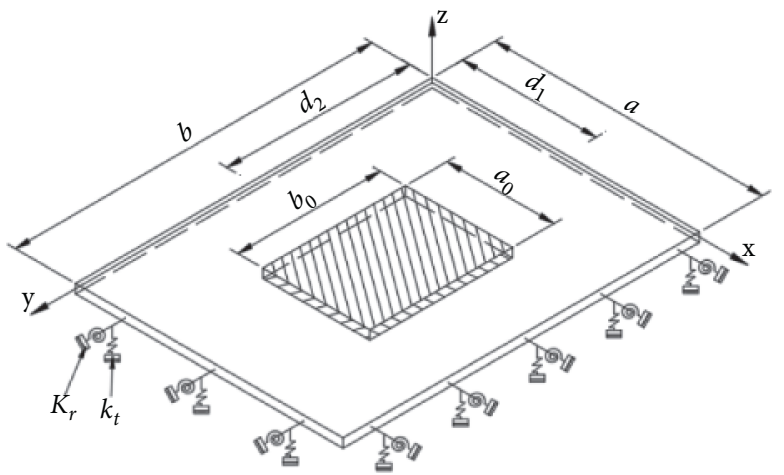

FIGURE 2: Locally heated laminated plate with elastic boundary subjected to local thermal load.

$$
\Pi=\pi+V,
$$

where $\pi$ is the bending strain energy of the laminated plate and $V$ is the potential energy of the laminated plate. They can be written as follows [13]:

$$
\begin{aligned}
\pi & =\frac{1}{2} \iint\left[N_{x} \varepsilon_{x}+N_{y} \varepsilon_{y}+N_{x y} \gamma_{x y}+Q_{x} \gamma_{x z}+Q_{y} \gamma_{y z}\right] \mathrm{d} x \mathrm{~d} y \\
& =\sum_{e=1}^{n}\left\{\frac{1}{2}\left\{q^{e}\right\}^{T}\left[K_{s}^{e}\right]\left\{q^{e}\right\}-\left\{q^{e}\right\}^{T}\left[F^{e}\right]\right\}=\frac{1}{2}\{q\}^{T}\left[K_{s}\right]\{q\}-\{q\}^{T}[F], \\
V & =\frac{1}{2} \iint\left[N_{x}\left(\frac{\partial w}{\partial x}\right)^{2}+2 N_{x y} \frac{\partial w}{\partial x} \times \frac{\partial w}{\partial y}+N_{y}\left(\frac{\partial w}{\partial y}\right)^{2}\right] d x d y=\sum_{e=1}^{n} \frac{1}{2}\left\{q^{e}\right\}^{T}\left[K_{\sigma}^{e}\right]\left\{q^{e}\right\} \\
& =\frac{1}{2}\{q\}^{T}\left[K_{\sigma}\right]\{q\},
\end{aligned}
$$

where $\left[K_{s}\right]$ is the stiffness matrix and $\left[K_{\sigma}\right]$ is the thermal stress stiffness matrix. The superscript $e$ denotes that these variables are defined on the element. $n$ is number of finite elements. $\{q\}$ is the nodal displacement vector.
2.2. Elastic Boundary. As demonstrated in Figure 2, the strain energy $U$ of the elastic boundary in the plate element can be represented by the following [14]:

$$
\begin{aligned}
U= & \frac{1}{2} \int_{0}^{b}\left[k_{t x 0} w^{2}+K_{r x 0}\left(\frac{\partial w}{\partial x}\right)^{2}\right]_{x=0} \mathrm{~d} y+\frac{1}{2} \int_{0}^{b}\left[k_{t x 1} w^{2}+K_{r x 1}\left(\frac{\partial w}{\partial x}\right)^{2}\right]_{x=a} \mathrm{~d} y \\
& +\frac{1}{2} \int_{0}^{a}\left[k_{t y 0} w^{2}+K_{r y 0}\left(\frac{\partial w}{\partial y}\right)^{2}\right]_{y=0} d x+\frac{1}{2} \int_{0}^{a}\left[k_{t y 1} w^{2}+K_{r y 1}\left(\frac{\partial w}{\partial y}\right)^{2}\right]_{y=b} \mathrm{~d} x,
\end{aligned}
$$

where $k_{t x 0}, k_{t x 1}, k_{t y 0}$, and $k_{t y 1}$ are the corresponding boundary support stiffnesses and $K_{r x 0} K_{r x 1}, K_{r y 0}$, and $K_{r y 1}$ are the corresponding boundary rotational stiffnesses of the composite laminated plate.

The stiffness matrix representation of the elastic boundary is obtained from the above equation as follows:

$$
U=\frac{1}{2}\{\delta\}_{e}^{T}\left\{K_{b}\right\}_{e}\{\delta\}_{e},
$$

where $\{\delta\}_{e}$ is the displacement vector of the element node, and the elastic boundary stiffness matrix $\left\{K_{b}\right\}_{e}$ can be expressed as follows: 


$$
\begin{aligned}
\left\{K_{b}\right\}_{e}= & \int\left(\frac{1}{2} k_{t x o}\left[N_{w}\right]^{T}\left[N_{w}\right]+\frac{1}{2} K_{r x 0}\left[N_{w}\right]^{T} \frac{\partial\left[N_{w}\right]}{\partial x}\right) \mathrm{d} y+\int 1\left(\frac{1}{2} k_{t x 1}\left[N_{w}\right]^{T}\left[N_{w}\right]+\frac{1}{2} K_{r x 1}\left[N_{w}\right]^{T} \frac{\partial\left[N_{w}\right]}{\partial x}\right) \mathrm{d} y \\
& +\int\left(\frac{1}{2} k_{t y 0}\left[N_{w}\right]^{T}\left[N_{w}\right]+\frac{1}{2} K_{r y 0}\left[N_{w}\right]^{T} \frac{\partial\left[N_{w}\right]}{\partial y}\right) \mathrm{d} x+\int\left(\frac{1}{2} k_{t y 1}\left[N_{w}\right]^{T}\left[N_{w}\right]+\frac{1}{2} K_{r y 1}\left[N_{w}\right]^{T} \frac{\partial\left[N_{w}\right]}{\partial y}\right) \mathrm{d} x,
\end{aligned}
$$

where $\left[N_{w}\right]$ is the element shape function.

The elastic boundary matrix of the composite laminated plate can be expressed as follows:

$$
\left[K_{b}\right]=\left[\begin{array}{llll}
k_{t x} & & & \\
& K_{r x} & & \\
& & k_{t y} & \\
& & & K_{r y}
\end{array}\right] .
$$

2.3. Vibration Eigenvalue Problem. When the composite laminated plate is in the critical buckling state corresponding to the neutral equilibrium condition, the second derivative of the total potential energy is set to zero; that is, the following buckling eigenvalue problem is obtained [2]:

$$
\left([K]+\lambda\left[K_{\sigma}\right]\right)[U]=0,
$$

where $[K]$ is the global stiffness matrix, namely, $[K]=\left[K_{s}\right]+$ $\left[K_{b}\right]$ and $\left[K_{s}\right]$ is the structural stiffness matrix. For thermal buckling, the product of $\lambda$ and the initial estimate $\Delta T$ are the critical buckling temperature. at which the plate buckles due to thermal stresses. $[U]$ represents the generalized displacement vector of the composite laminated plate.

The vibration eigenvalue problem of the laminated plate subjected to local thermal loading and the thermal load can be expressed as follows [15]:

$$
\left([K]+\left[\lambda K_{\sigma}\right]-\omega^{2}[M]\right)[U]=0,
$$

where $[M]$ is the mass matrix of the composite laminated plate and $\omega$ represents the vibration frequency.

\section{Numerical Results and Discussion}

A schematic diagram of the composite laminated plate subjected to local thermal loading and the coordinate system is shown in Figure 2. The composite laminated plate is made of carbon/epoxy with the following material and geometric properties (unless otherwise stated): the physical material parameters and structural dimensions of the laminated plate are as follows: density $\rho=1520 \mathrm{~kg} / \mathrm{m}^{3}, E_{1}=133.86 \mathrm{Gpa}$, $E_{2}=7.706 \mathrm{Gpa}, G_{12}=4.302 \mathrm{Gpa}, \nu_{12}=0.301, \alpha_{1}=0.32 \mathrm{E}$ $-6 \mathrm{C}^{-1}, \alpha_{2}=25.89 E-6^{\circ} \mathrm{C}^{-1}$, and $\alpha_{3}=0 \mathrm{~K}^{-1}$, the layer of alternately composite laminated plate is $[0 / 90 / 0$ $190 / 90 / 0 / 90 / 0]$, the length, width, and thickness of the laminated plate are represented by $a, b$, and $t$, the size of the heated area is in the form of $a_{0}$ and $b_{0}$, and the distance between the centre of heated area and the border of the laminated plates is, respectively, denoted by $d_{1}$ and $d_{2}$. The boundary support stiffness and boundary rotational stiffness are unchanged along the boundary of the composite laminated plate in the paper; in other words, all the boundary support stiffnesses are denoted by $k_{t}$, and the boundary rotational stiffness can be denoted as $K_{r}$.

3.1. Model Validation. To verify the accuracy of the model, the natural frequencies of the orthotropic plate subjected to thermal loading are calculated and compared with the literature. The geometric dimensions and physical parameters are as follows: $a=1 \mathrm{~m}, b=1.5 \mathrm{~m}, \rho=2100 \mathrm{~kg} / \mathrm{m}^{3}$, $t=0.001 \mathrm{~m}, E_{1}=120 \mathrm{Gpa}, E_{2}=120 \mathrm{Gpa}, G_{12}=44.4 \mathrm{Gpa}$, $v_{12}=0.25, \alpha_{1}=4 E-8 \mathrm{~K}^{-1}, \alpha_{2}=4 e-8 \mathrm{~K}^{-1}$, and $\alpha_{3}=0 \mathrm{~K}^{-1}$; the initial temperature is $T_{0}=293.15 \mathrm{~K}^{-1}$; the grid is $48 \times 48$; and the natural frequencies of orthotropic plates with three groups of boundary conditions are shown in Tables 1 and 2 ( $s$ represents simply supported and $c$ represents rigidly fixed). The computed result is in good agreement with results in the literature.

Next, the critical temperature of the composite laminated plate is verified. The geometrical dimensions and the physical parameters of the composite laminated plate are shown as follows: $a=0.6 \mathrm{~m}, b=0.4 \mathrm{~m}, \rho=1570 \mathrm{~kg} / \mathrm{m}^{3}$, $t=0.005 \mathrm{~m}, E_{1}=132 \mathrm{Gpa}, E_{2}=10.3 \mathrm{Gpa}, G_{12}=6.5 \mathrm{Gpa}$, $G_{13}=6.5 \mathrm{Gpa}, G_{23}=3.91 \mathrm{Gpa}, v_{12}=0.3, \alpha_{1}=1.2 e-6 /{ }^{\circ} \mathrm{C}$, $\alpha_{2}=2.4 e-5 /{ }^{\circ} \mathrm{C}$, and $\alpha_{3}=0 \mathrm{~K}^{-1}$, and the layer of alternately laminate is $[0 / 90 / 90 / 0]$. The critical temperature of the laminated plate with rigid fixed boundary condition is shown in Table 3, and the numerical results are in good agreement with the results in the literature.

The next step is to calculate the natural frequencies of the laminated plate. The geometrical size of the plate is $a=$ $0.15 \mathrm{~m}$ and $b=0.15 \mathrm{~m}$, and the boundary condition is CFFF; that is, one side is rigidly fixed and the other side is a free boundary. Material I is glass/epoxy resin, the density of the laminated plate is $\rho=1420.05 \mathrm{~kg} / \mathrm{m}^{3}$, the thickness of the laminated plate is $t=0.002 \mathrm{~m}$, and the layer of the composite laminated plate is [0/90/0/90/0/90]. The physical parameters of the composite laminated plate are as follows: $E_{1}=7.205 \mathrm{Gpa}, \quad E_{2}=6.327 \mathrm{Gpa}, \quad G_{12}=2.8 \mathrm{Gpa}, \quad G_{13}=$ $2.8 \mathrm{Gpa}, \mathrm{G}_{23}=1.4 \mathrm{Gpa}$, and $\nu_{12}=0.17$. Material II is carbon/epoxy resin, the density of the composite laminated plate is $\rho=1388 \mathrm{~kg} / \mathrm{m}^{3}$, the thickness of the composite laminated plate is $t=0.00375 \mathrm{~m}$, the layer of the composite laminated plate is $[45 /-45 /-45 / 45]$, and its physical parameters are as follows: $E_{1}=6.469 \mathrm{Gpa}, E_{2}=5.626 \mathrm{Gpa}$, $G_{12}=2.05 \mathrm{Gpa}, \quad G_{13}=2.05 \mathrm{Gpa}, \quad G_{23}=1.025 \mathrm{Gpa}, \quad$ and $v_{12}=0.3$. The natural frequencies of the composite laminated plate are consistent with the results in references, as shown in Table 4 . The slight difference between the numerical and experimental results is caused by the limitations of the ideal boundary conditions of the laminated plate. 
TABLE 1: Natural frequencies of the heated orthotropic plate $\left(\mathrm{Hz} ;{ }_{T}=303.15 \mathrm{~K}^{-1}\right)$.

\begin{tabular}{|c|c|c|c|c|c|c|}
\hline \multirow{2}{*}{ Order modal } & \multicolumn{2}{|c|}{$S-S-C-C$} & \multicolumn{2}{|c|}{$S-C-C-C$} & \multicolumn{2}{|c|}{$C-C-C-C$} \\
\hline & Present solution & Kai et al. [16] & Present solution & Kai et al. [16] & Present solution & Kai et al. [16] \\
\hline 1 & 6.151 & 6.100 & 6.726 & 6.604 & 8.915 & 8.719 \\
\hline 2 & 11.081 & 11.027 & 12.594 & 12.493 & 13.993 & 13.776 \\
\hline 3 & 18.469 & 18.441 & 18.733 & 18.683 & 22.820 & 22.646 \\
\hline 4 & 19.475 & 19.421 & 21.886 & 21.797 & 22.825 & 22.743 \\
\hline 5 & 23.087 & 23.039 & 24.023 & 23.929 & 27.524 & 27.352 \\
\hline 6 & 31.047 & 30.990 & 32.847 & 32.730 & 35.127 & 34.949 \\
\hline 7 & 31.184 & 31.087 & 34.447 & 34.321 & 35.704 & 35.486 \\
\hline 8 & 37.951 & 37.885 & 38.120 & 38.044 & 44.048 & 43.938 \\
\hline
\end{tabular}

TABLe 2: Natural frequencies of the heated orthotropic plate $\left(\mathrm{Hz}{ }_{T}=313.15 \mathrm{~K}^{-1}\right)$.

\begin{tabular}{|c|c|c|c|c|c|c|}
\hline \multirow{2}{*}{ Order modal } & \multicolumn{2}{|c|}{$S-S-C-C$} & \multicolumn{2}{|c|}{$S-C-C-C$} & \multicolumn{2}{|c|}{$C-C-C-C$} \\
\hline & Present solution & Kai et al. [16] & Present solution & Kai et al. [16] & Present solution & Kai et al. [16] \\
\hline 1 & 5.014 & 4.933 & 5.680 & 5.493 & 8.118 & 7.589 \\
\hline 2 & 9.977 & 9.908 & 11.592 & 11.469 & 13.076 & 12.801 \\
\hline 3 & 17.445 & 17.415 & 17.718 & 17.662 & 21.861 & 21.669 \\
\hline 4 & 18.402 & 18.343 & 20.899 & 20.802 & 21.945 & 21.856 \\
\hline 5 & 22.038 & 21.984 & 23.000 & 22.896 & 26.596 & 26.408 \\
\hline 6 & 29.986 & 29.925 & 31.824 & 31.700 & 34.151 & 33.964 \\
\hline 7 & 30.127 & 30.026 & 33.458 & 33.328 & 34.738 & 34.505 \\
\hline 8 & 36.934 & 36.866 & 37.104 & 37.027 & 43.129 & 43.016 \\
\hline
\end{tabular}

TABLE 3: Critical temperature of the heated laminated plate $\left({ }^{\circ} \mathrm{C}\right)$.

\begin{tabular}{lcccccccc}
\hline Order modal & 1 & 2 & 3 & 4 & 5 & 6 & 7 \\
\hline Present solution & 89.67 & 156.20 & 168.41 & 193.73 & 287.23 & 295.45 & 301.82 \\
Li et al. [17] & 89.88 & 156.32 & 168.88 & 194.04 & 290.52 & 297.99 & 304.77 & 314.79 \\
Error (\%) & 0.2 & 0.08 & 0.28 & 0.16 & 1.13 & 0.85 & 0.97 \\
\hline
\end{tabular}

TABLE 4: Experimental validations of the natural frequencies of the laminated plate.

\begin{tabular}{lcccccc}
\hline \multirow{2}{*}{ Order modal } & \multicolumn{3}{c}{ Materials I } & \multicolumn{3}{c}{ Materials II } \\
& Numerical solution [18] & Trial [18] & Present solution & Numerical solution [18] & Trial [18] & Present solution \\
\hline 1 & 29.431 & 28 & 28.892 & 56.038 & 62.5 & 56.223 \\
2 & 79.319 & 68 & 76.345 & 140.29 & 152 & 142.542 \\
3 & 183.400 & 164 & 183.214 & 340.2 & 378 & 343.786 \\
4 & 236.26 & 234 & 235.995 & 441.53 & 485 & 443.468 \\
5 & 278.97 & 267 & 277.567 & 503.23 & 561 \\
\hline
\end{tabular}

3.2. Factors That Influence Critical Temperatures and Vibration Frequencies. It is necessary to investigate the determining factor for the buckling failure of composite laminated plates with elastic boundaries subjected to local thermal loads. The numerical results of nonuniform in-plane resultant forces due to thermal load were presented. The following values were taken: $a=0.5 \mathrm{~m}, b=0.5 \mathrm{~m}$, $t=0.00625 \mathrm{~m}, a_{0}=0.2 \mathrm{~m}$, and $b_{0}=0.2 \mathrm{~m}$. Figure 3 shows typical cases of the in-plane resultant force distribution for a composite laminated plate at the buckling temperature. The compressive forces in both the $x$ and $y$ directions over the heated region dominate the occurrence of thermal buckling. In addition, comparatively small values of in-plane shear resultant forces $N_{x y}$ can be found at four corners of the heated region.
3.2.1. Boundary Conditions. The size of the composite laminated plate is $a=1 \mathrm{~m}, b=1 \mathrm{~m}$, and $t=a / 50$, the layer of composite laminated plate is $[0 / 90 / 90 / 0]$, and the surrounding boundary adopts the same constraint. The curve showing the change in critical temperature of the composite laminated plate with boundary support stiffness and boundary rotation stiffness varies (free boundary-simply supported boundary-rigid fixed boundary) and is shown in Figure 4. There are two first-order critical temperatures in Figure 4. The figure shows that there are two stages in which the critical temperature increases sharply, and the influence of the boundary support stiffness is greater for the secondorder critical temperature than the first-order critical temperature, i.e., the boundary support stiffness changes from $k_{t}=1 e 5 \mathrm{~Pa}$ to $k_{t}=1 e 7 \mathrm{~Pa}$. In the second stage, i.e., the 


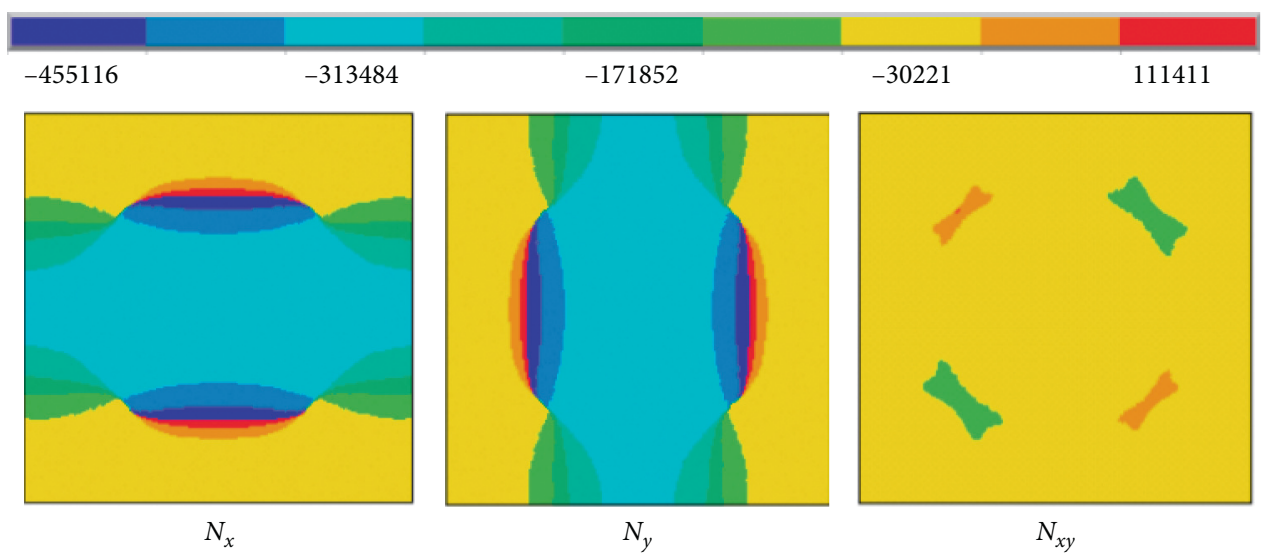

FIGURE 3: The variation over the plate of the in-plane resultant forces $(\mathrm{N} / \mathrm{m})$.

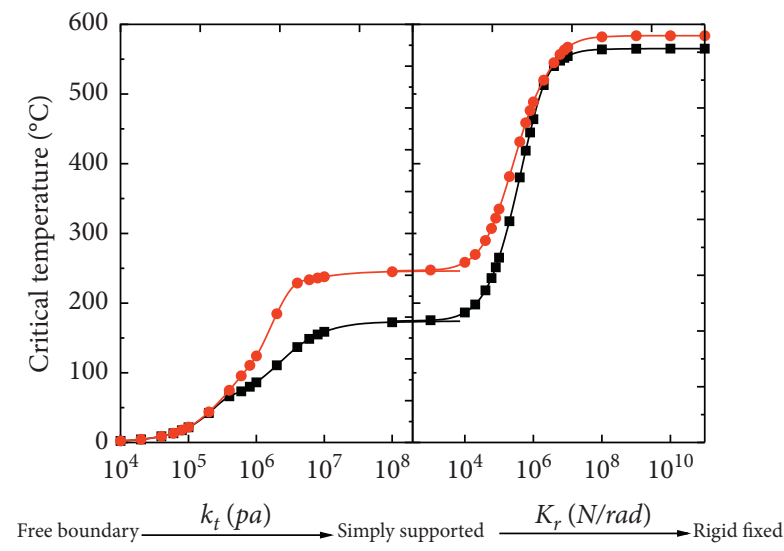

FIGURE 4: Effects of elastic boundary stiffnesses on the critical temperatures of composite laminated plates.

boundary rotational stiffness changes from $k_{r}=1 e 4 \mathrm{~N} / \mathrm{rad}$ to $k_{r}=1 e 8 \mathrm{~N} / \mathrm{rad}$, the two first-order critical temperatures of the composite laminated plate increase significantly, and the increased temperature range of the second stage is larger than that of the first stage, which indicates that the boundary rotational stiffness ratio has a greater influence on the critical temperature of the composite laminated plate.

3.2.2. Heating Position. The geometric size and physical parameters of the composite laminated plate are taken as $a=1 \mathrm{~m}, b=1 \mathrm{~m}, t=a / 100, a_{0}=0.4 \mathrm{~m}$, and $b_{0}=0.4 \mathrm{~m}$. The distance $d_{2}=0.5 b$ remains unchanged, i.e., only $d_{1}$ changes from $0.2 a$ to $0.5 a$ when the heating position is changed. The curve of critical temperature vs. heating position varies as shown in Figure 5. The critical temperature of the composite laminated plate increases gradually when the boundary support stiffness is small $(5 e 4 \mathrm{~Pa})$. The critical temperature of the composite laminated plate decreases gradually mainly because the boundary stiffness of composite laminated plates is smaller than the stiffness of the laminated plates, and the boundary of the composite laminated plates is basically unrestricted. However, the composite laminated plate is not prone to buckling when there is thermal load near the

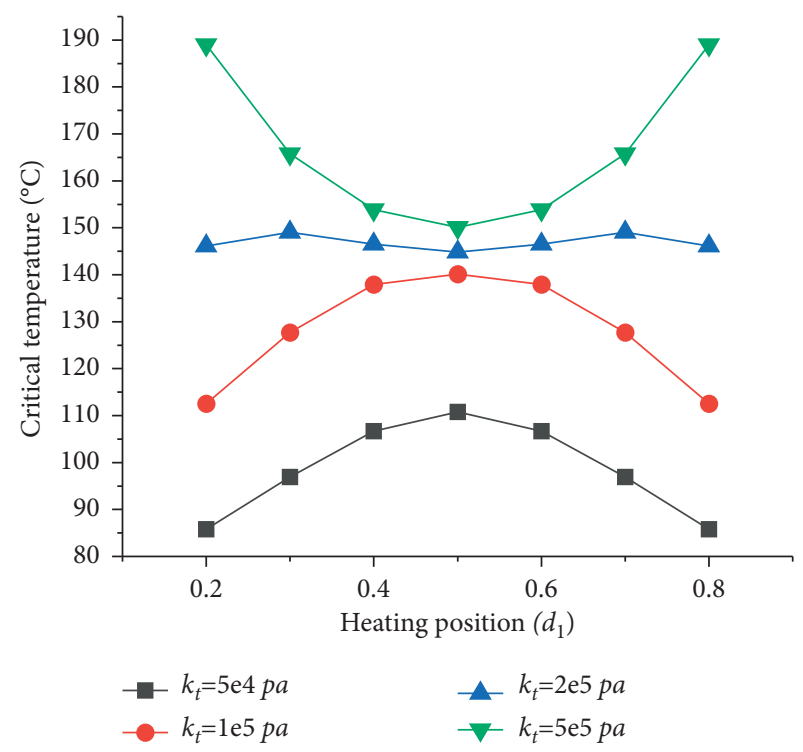

FIGURE 5: Critical temperatures of composite laminated plates with different heating positions.

boundary, and the stiffness of the boundary support is greater than $2 e 5 \mathrm{~Pa}$, as shown in Figure 5. The variation trend is basically unchanged when the stiffness of the boundary support reaches a certain value. As the stiffness of the boundary support is infinite and the rotational stiffness of the boundary increases gradually, the difference in the critical temperature of the composite laminated plate increases when the heating position is at the boundary $\left(d_{1}=0.2 a\right)$ and the heating position is in the middle of the composite laminated plate $\left(d_{1}=0.5 a\right)$, as shown in Figure 6 . The boundary stiffness has an important influence on the position of the minimum temperature required for buckling locally heated composite laminates; that is, the position of the minimum critical temperature is closer to the boundary when the boundary stiffness is small, while the position of the minimum critical temperature is at the midpoint, the boundary stiffness is large. In other words, the influence of boundary stiffness on the minimum critical temperature of laminates mainly depends on the relative stiffness of the 


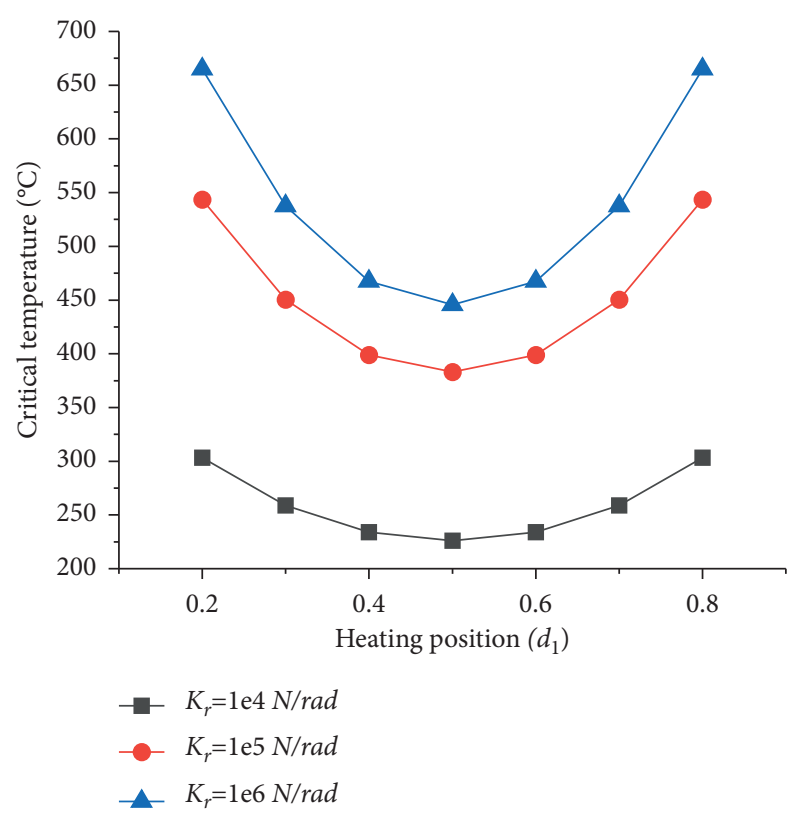

FIGURE 6: Critical temperatures of composite laminated plates with different heating positions.

boundary and the plates. For example, when the boundary support stiffness is small, that is, the relative stiffness between the boundary and the laminate is small, the laminate is more prone to buckling when the local thermal load is near the boundary.

3.2.3. Heated Area. The curve of critical temperature vs. heating area of the laminated plate structure is shown in Figure 7 where $d_{1}=0.5 a, d_{2}=0.5 b, k_{t}=1 e 7 \mathrm{~Pa}$, and $K_{r}=1 e 6 \mathrm{~N} / \mathrm{rad}$. The critical temperature of the composite laminated plate is large when the heated area is small, and it decreases rapidly when the critical area gradually increases. The critical temperature decreases slowly when the heated area exceeds approximately $10 \%$ of the total area of the composite laminated plate. Therefore, the thermal buckling of locally heated composite laminated plates is generally not checked in practical applications, and thermal buckling calculations are necessary only when the heated area is large and the thermal load is high.

\subsection{Vibration Frequencies of a Composite Laminated Plate} Subjected to Local Thermal Loading. Assuming size of the laminated plate is $a=1 \mathrm{~m}, b=1 \mathrm{~m}$, and $t=a / 100 \mathrm{~m}$, the thermal load is set as the critical temperature when the heating area is the whole laminated plate, so the fundamental frequency of the composite laminated plate is equal to $0 \mathrm{~Hz}$ when the heated area is equal to the laminated plate area. The curve of the fundamental frequency of the composite laminated plate vs. heating area for boundary conditions is shown in Figure 8. The fundamental frequency of the laminated plate decreases with increase in heated area. The effect of the heating area on the fundamental frequency of the composite laminated plate becomes greater when the

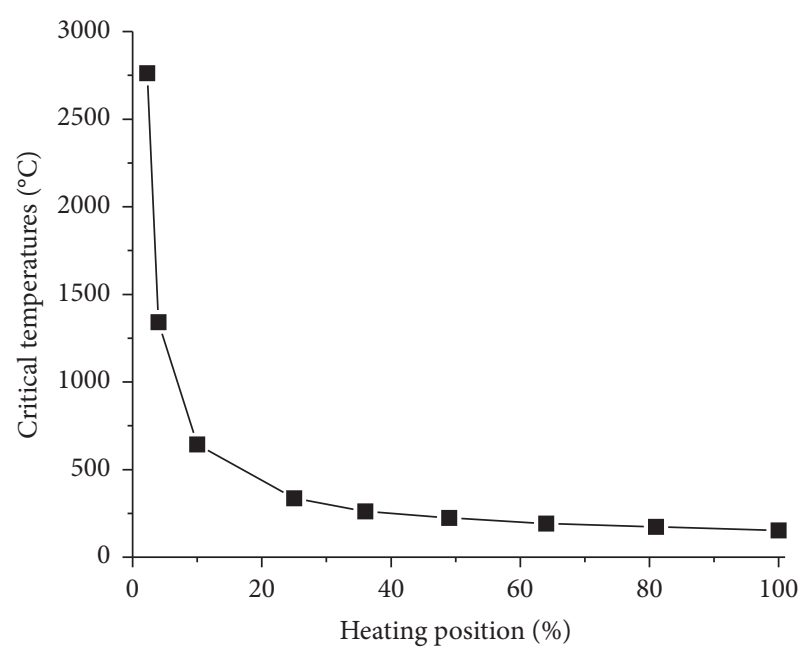

FIGURE 7: Critical temperatures of composite laminated plates with different heating areas.

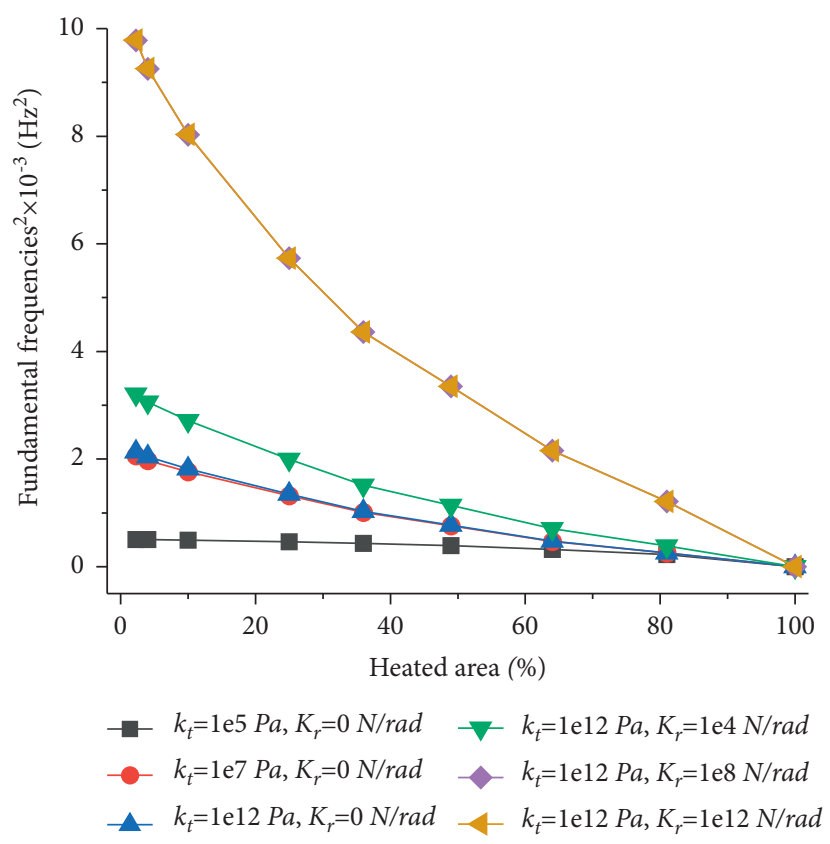

Figure 8: Fundamental frequencies of composite laminated plates with different heating areas.

boundary constraint is strengthened. For example, when $k_{t}=1 e 5 \mathrm{~Pa}$ and $K_{r}=0 \mathrm{~N} / \mathrm{rad}$ and the heating area increases from $10 \%$ to $25 \%$, the fundamental frequency of the composite laminated plate decreases by $8 \%$. When $k_{t}=1 e 12 \mathrm{~Pa}$ and $K_{r}=1 \mathrm{e} 12 \mathrm{~N} / \mathrm{rad}$ and the heating area increases from $10 \%$ to $25 \%$, the fundamental frequency of the composite laminated plate decreases by $15 \%$. In addition, the two stages of the sharp increase in fundamental frequency have nothing to do with the heated area but are related to the boundary conditions.

Assuming size of the laminated plate is $a=0.5 \mathrm{~m}, b=$ $0.5 \mathrm{~m}$ and $t=a / 80 \mathrm{~m}$. When $a_{0}=0.4 a$ and $b_{0}=0.4 b$, the heating area is $16 \%$ of the entire area of the composite laminated plate, and the thermal load is the minimum 


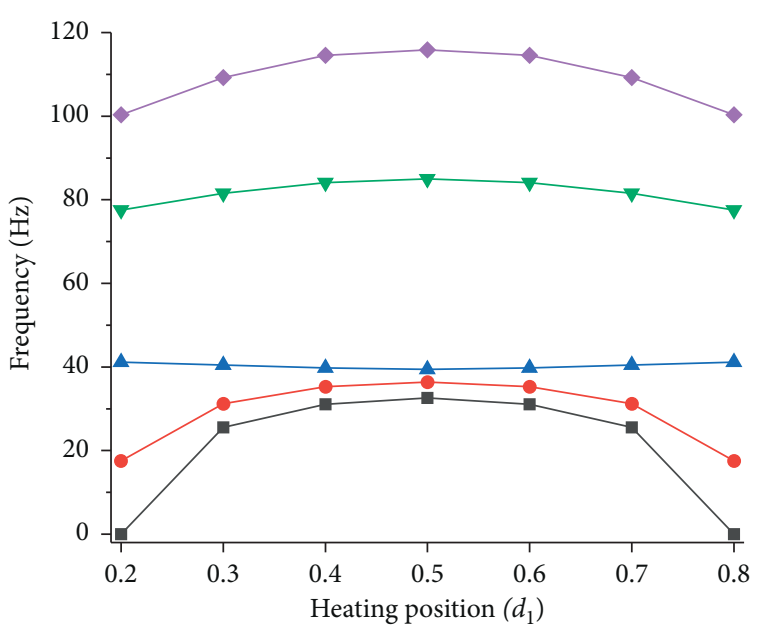

(a)

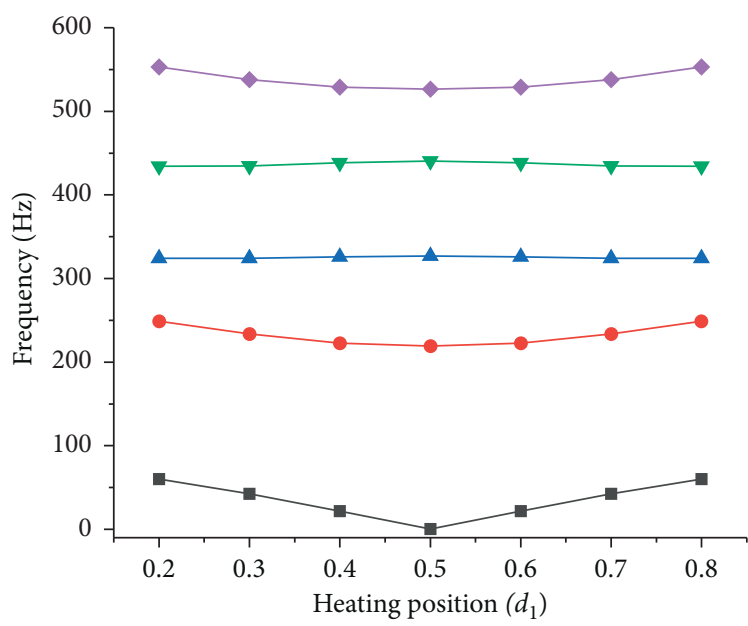

(c)

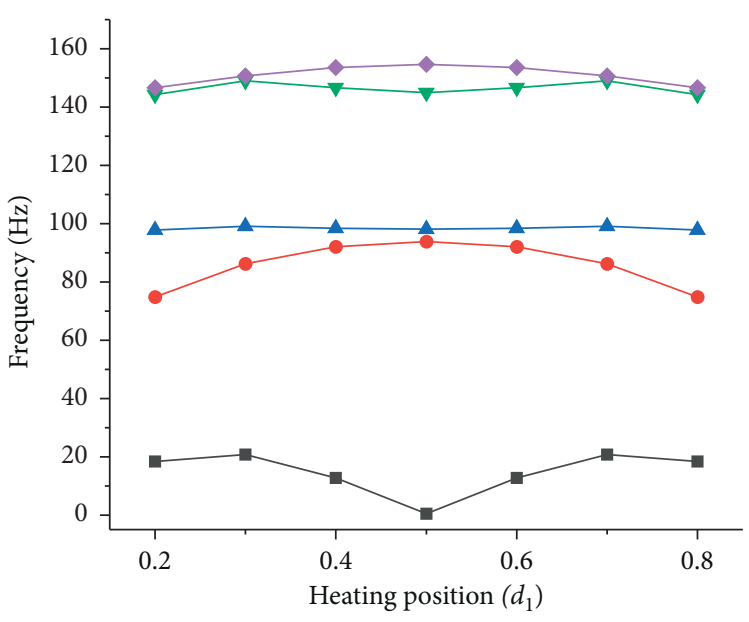

(b)

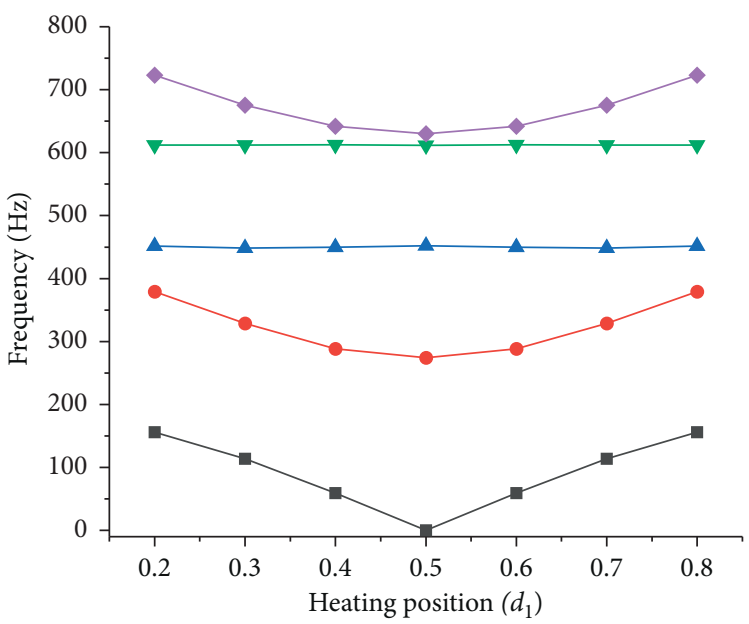

(d)

FIGURE 9: Vibration frequencies of composite laminated plates with different heating positions: (a) $k_{t}=1 e 5 \mathrm{~Pa}$ and $K_{r}=0 \mathrm{~N} / \mathrm{rad}$; (b) $k_{t}=4 e 5 \mathrm{~Pa}$ and $K_{r}=0 \mathrm{~N} / \mathrm{rad}$; (c) $k_{t}=1 e 15 \mathrm{~Pa}$ and $K_{r}=0 \mathrm{~N} / \mathrm{rad}$; (d) $k_{t}=1 e 15 \mathrm{~Pa}$ and $K_{r}=1 e 15 \mathrm{~N} / \mathrm{rad}$.

critical temperature of the laminated plate structure when the heating position changes. The curves of the frequency change of the composite laminated plate at different heating positions are shown in Figure 9. As shown in the figure, the first-order frequency of the composite laminated plate is large when the boundary supports stiffness $k_{t}=1 e 5 \mathrm{~Pa}$ and $K_{r}=0 \mathrm{~N} / \mathrm{rad}$, and the heating position is close to the centre of the laminated plates. The first-order frequency of the composite laminated plate is the smallest when the heating position is the centre of the composite laminated plate, and it is the largest when the stiffness of the boundary support increases to $k=4 e 5 \mathrm{~Pa}$ and $K_{r}=0 \mathrm{~N} / \mathrm{rad}$, and the heating position is approximately $d_{1}=0.3 \mathrm{a}$. The thermal stress of the composite laminated plate caused by the thermal load is larger due to the enhancement of the boundary stiffness when the boundary support stiffness continues to increase to $k=1 e 15 \mathrm{~Pa}$ and $K_{r}=0 \mathrm{~N} / \mathrm{rad}$; in this instance, the firstorder frequency of the composite laminated plate is the smallest when the heating position is at the centre of the laminated plate. When the boundary support stiffness continues to increase to $k=1 e 15 \mathrm{~Pa}$ and $K_{r}=0 \mathrm{~N} / \mathrm{rad}$, the boundary condition is equivalent to rigid fixation, and the difference between the first-order frequencies of the composite laminated plate increases when the heating area is at the boundary and central position because the boundary constraint is strengthened and the thermal stress difference of the composite laminated plate increases.

\section{Conclusions}

There are two stages in which the critical temperature increases sharply during the transition from a free boundary to a simply supported boundary and a rigid fixed boundary. The effect of the boundary rotational stiffness on the critical temperature of the composite laminated plate is greater than that of the boundary support stiffness. When the stiffness of the boundary support is small, the composite laminated plate is prone to buckling if the local temperature load is near the boundary. However, buckling easily occurs when the local temperature load is located at the centre of the laminate if the boundary support stiffness reaches a certain value. The thermal buckling of locally heated laminated plates is 
generally not checked in practical applications. It is necessary to carry out thermal buckling calculations only when the heated area exceeds approximately $10 \%$ of the total laminate area.

When the stiffness of the boundary support is small, the frequency of the composite laminated plate increases as the heating position approaches the centre of the laminated plate. When the stiffness of the boundary support reaches a certain value, the fundamental frequency of the laminated plate decreases as the heating position approaches the centre of the composite laminated plate. The stronger the boundary constraint is, the greater the influence of the heating area is on the vibration frequencies of the composite laminated plate.

\section{Data Availability}

The data generated or analyzed during this study are included in this article.

\section{Conflicts of Interest}

The author declares that there are no conflicts of interest regarding the publication of this paper.

\section{Acknowledgments}

This project was supported by the Science and Technology Research Program of Chongqing Municipal Education Commission (Grant no. KJQN202100746).

\section{References}

[1] V. O. John, S. A. Buehler, A. V. Engeln et al., "Understanding the variability of clear-sky outgoing long-wave radiation based on ship-based temperature and water vapour measurements," Quarterly Journal of the Royal Meteorological Society, vol. 132, no. 621, pp. 2675-2691, 2010.

[2] P. Vangipuram and N. Ganesan, "Buckling and vibration of rectangular composite viscoelastic sandwich plates under thermal loads," Composite Structures, vol. 77, no. 4, pp. 419-429, 2007.

[3] P. Jeyaraj, N. Ganesan, and C. Padmanabhan, "Vibration and acoustic response of a composite plate with inherent material damping in a thermal environment," Journal of Sound and Vibration, vol. 320, no. 1-2, pp. 322-338, 2009.

[4] L.-C. Shiau, S.-Y. Kuo, and C.-Y. Chen, "Thermal buckling behavior of composite laminated plates," Composite Structures, vol. 92, no. 2, pp. 508-514, 2010.

[5] M. Biswal, S. K. Sahu, and A. V. Asha, "Experimental and numerical studies on free vibration of laminated composite shallow shells in hygrothermal environment," Composite Structures, vol. 127, pp. 165-174, 2015.

[6] T. Zhao, Z. Yang, and W. Tian, "Vibration and acoustic radiation characteristics analysis of composite laminated plate in hygrothermal environments," in Proceedings of the 25th International Congress on Sound and Vibration(ICSV25), vol. 38, no. 10, Article ID 221038, Hiroshima Japan, July 2017.

[7] W. L. Ko, Thermal Buckling Analysis of Rectangular Panels Subjected to Humped Temperature Profile heating, Technical Report No. NASA/TP-2004 21204, CA, USA, H-2539. NASA Dryden Flight Research Center, 2004.
[8] S. Alimirzaei, M. Mohammadimehr, and A. Tounsi, "Nonlinear analysis of viscoelastic micro-composite beam with geometrical imperfection using FEM: MSGT electro-magneto-elastic bending, buckling and vibration solutions," Structural Engineering and Mechanics, vol. 71, no. 5, pp. 485-502, 2019.

[9] H. Hirane, M. O. Belarbi, M. Houari, and A. Tounsi, "On the layerwise finite element formulation for static and free vibration analysis of functionally graded sandwich plates," Engineering with Computers, 2021.

[10] W. Li and Y. Li, "Vibration and sound radiation of an asymmetric laminated plate in thermal environments," Acta Mechanica Solida Sinica, vol. 28, no. 1, pp. 11-22, 2015.

[11] A. Avci, S. Kaya, and B. Daghan, "Thermal buckling of rectangular laminated plates with a hole," Journal of Reinforced Plastics and Composites, vol. 24, no. 3, pp. 259-272, 2005.

[12] E. J. Barbero, Introduction to Composite Materials Design, Crc Press, Boca Raton, FL, US, 2nd edition, 2010.

[13] W. J. Chen, P. D. Lin, and L. W. Chen, "Thermal buckling behavior of thick composite laminated plates under nonuniform temperature distribution," Computers \& Structures, vol. 41, no. 4, pp. 637-645, 1991.

[14] O. Chiello, F. Sgard, and N. Atalla, "On the use of a component mode synthesis technique to investigate the effects of elastic boundary conditions on the transmission loss of baffled plates," Computers and Structures, vol. 81, no. 28-29, pp. 2645-2658, 2003.

[15] W. Zhao and R. K. Kapania, "Vibration analysis of curvilinearly stiffened composite panel subjected to in-plane loads," AIAA Journal, vol. 55, no. 3, pp. 1-17, 2016.

[16] Z. Kai, J. Su, and H. Hua, "Closed form solutions for vibration and sound radiation of orthotropic plates under thermal environment," International Journal of Structural Stability and Dynamics, vol. 18, no. 7, Article ID 1850098, 2018.

[17] X. Li, K. Yu, J. Han, H. Song, and R. Zhao, "Buckling and vibro-acoustic response of the clamped composite laminated plate in thermal environment," International Journal of Mechanical Sciences, vol. 119, pp. 370-382, 2016.

[18] N. Sharma, T. R. Mahapatra, and S. K. Panda, "Numerical study of vibro-acoustic responses of un-baffled multi-layered composite structure under various end conditions and experimental validation," Latin American Journal of Solids and Structures, vol. 14, no. 8, pp. 1547-1568, 2017. 